\title{
Evaluation of A Mobile Learning System to Support Correct Medication Use for Health Promotion
}

\author{
Ya-Ming Shiue ${ }^{1}$ \\ "Yu-Chiung Hsu ${ }^{2}$ \\ Meng-Huei Sheng ${ }^{1}$ \\ Cheng-Hsuan Lan ${ }^{1}$
}

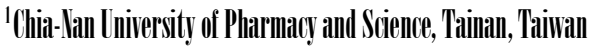

${ }^{2}$ Kunt-Shatll Iniversity, Thininall, Taiwiwill

Recently, the applications of mobile technology integration into innovative pedagogical approaches have resulted in new opportunities and challenges. The rapid development of mobile technology encourages student participation, knowledge sharing, collaboration, and the social interaction necessary to form authentic learning communities around student-generated content anytime and anywhere. Most health education interventions remain focused on traditional lecture methods and neglect the importance of student-centered learning approaches, few studies have examined the effectiveness of mobile technology on health promotion. Therefore, this paper designed a mobile learning system for learning correct medication use and investigated students' continuance usage intention. The findings revealed that students' satisfaction with mobile learning was the major factor predicting continuance intention.

Keywords: Mobile learning system, mobile technology, intention, correct medication use, health promotion

JEL : D83, I10
\end{abstract}

Health education is a crucial component of the delivery of health knowledge and improves both mental and physical health. Rural Taiwanese residents regularly receive messages about the use of medicine from Internet, television, and radio commercials. These messages often are incorrect and can easily lead to medication errors. In order to expand the range of safe medication, Health-promoting School Program (HPS) was launched in 2009 by the Taiwan Food and Drug Administration, the Taiwan Ministry of Education, and the Taiwan Pharmacy Association (Chi et al., 2014). The HPS program was implemented in 14 cities in Taiwan. Teachers and pharmacists together developed different kinds of teaching materials and activities based on correct medication usage. The results indicated that HSP program had a positive effect on enhancing students' abilities of correct medication use.

With the development and popularity of mobile and wireless technologies, mobile technology is providing better and broader educational applications than traditional classroom settings due to its convenience, connectivity, personalization, and degree of interaction (Sharples, 2000). Learning with mobile technology has great potential for facilitating more innovative educational methods and mobile

\footnotetext{
Manuscript received October 9, 2018; revised December 31, 2018; accepted

January 15, 2019. (C) The Author(s); CC BY-NC; Licensee IJMESS

Special Issue (ICMHI 2018)

*Corresponding author: ychsu@mail.ksu.edu.tw
} 
learning has thus become increasingly more popular. A growing number of researchers have identified multiple educational settings for mobile learning, including science (Liu et al., 2009), mathematics (Song and Kim, 2015), and history (King et al., 2014) focused on the impacts of on student achievement. Sung et al. (2016) concluded that learners using a mobile technology perform significantly better in terms of achievement than those who are not using mobile technology. Therefore, we would like to use the convenience of mobile learning to expand the effect of correct medication usage.

Researchers have focused on predicting and the adoption and satisfaction of mobile learning based on technology acceptance model (TAM) (Davis, 1989). Hyman, Moser and Segala (2014) extended TAM and added learnability to evaluate its effects on behavioral intention and usage. The findings suggested learnability did not show the significance on behavioral intention and usage. Alrasheedi, Capretz and Raza (2015) examined 14 factors which might impact mobile learning implementation. The results showed that perceived productivity was the primary factor to successfully apply mobile learning. Pindeh, Suki and Suki (2016) proposed a research framework which incorporated TAM model on perceived playfulness to predict uses' behavioral intention in mobile learning. Although, researchers had paid much attention on acceptance and perception, while the long-term usage was crucial to the success of mobile learning. However, little research has been done on the continuance use intention of mobile learning, especially in the field of health education. This study aimed to investigate the factors that affect students' continuance intention to use mobile learning in health education. Therefore, we developed a mobile learning system related to correct medication usage and investigated the learning outcome and the continuance intention for mobile learning. Prior studies suggested that expectationconfirmation model (ECM) (Bhattacherjee, 2001) has successfully explained and predicted the users' intentions to continue using e-learning (Lee, 2010). In addition, perceived enjoyment was a stronger predictor for users' intention in mobile learning (Pindeh et al., 2010). In this study, we incorporated the ECM and perceived enjoyment to investigate students' continuance intention to use mobile learning related to correct medication usage.

\section{LITERATURE REVIEW}

\section{Correct Medication Usage}

According to Chi et al.'s (2012) study on correct medication usage, there are five core abilities related to correct medication usage, including the ability to clearly express personal conditions to one's physician, the ability to check information on medication packages, the ability to correctly take medications as prescribed, the ability to be the one's own master when taking medications, and the 
Shiue et al.

ability to be friends with pharmacists and physicians. In order to promote essential information of correct medication usage to enhance health literacy and improve health outcomes, Taiwan Food and Drug Administration, the Taiwan Ministry of Education initiated the Health-promoting School Program (HPS) in 2009 in Taiwan. Chi et al. (2014) evaluated the effects of the HSP program and the results indicated that implementation of correct medication usage had significantly enhanced students' health knowledge of correct medication usage.

With the rapid development of information and communication technologies, it enables knowledge to be processed and transmitted more quickly than ever. The rise of information technology is providing significant support for spreading health literacy and related knowledge. Shiue and Hsu (2017) investigated the effectiveness of a digital game related to correct medication usage. The results showed that game-based learning significantly enhanced students' knowledge of correct medication usage. The convenience of mobile technologies offering students the opportunities to engage in asynchronous and ubiquitous learning environments. As mentioned above, little research has been focused on the continuance usage intention of mobile learning to enhance health literacy. In order to fill this gap, we develop a mobile learning system (Figure 1) to investigate the outcomes of mobile learning.

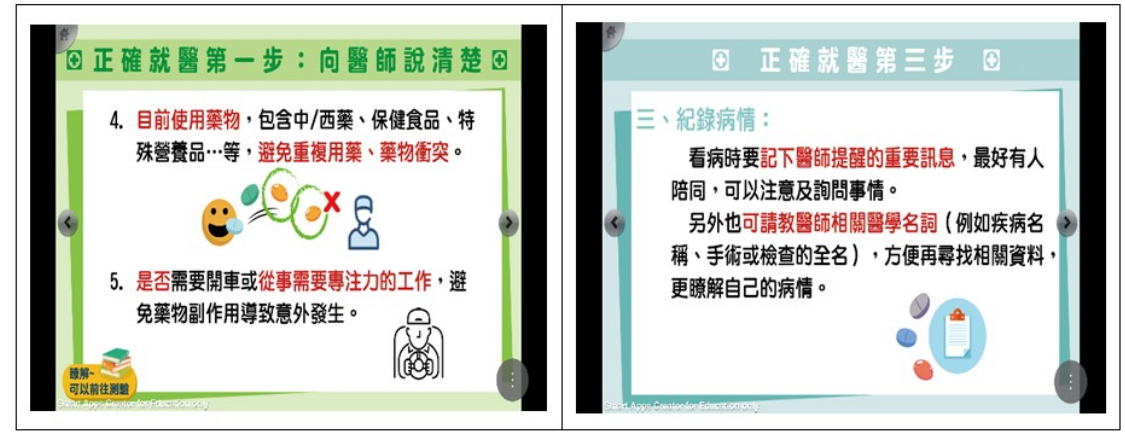

Source: Developed for this study

Figure 1. Sample Correct Medication Use

\section{Expectation Confirmation Model (ECM)}

The expectation-confirmation model (Bhattacherjee, 2001) is based on integrating the TAM (Davis, 1989 ) with the expectation-confirmation theory (Oliver, 1980) to understand users' intention to continue using information systems (IS). The essence of the expectation-confirmation model (ECM) is that actual consumption experience will be compared with original expectations and adjusted while they are experienced with the products and the resulting confirmation will lead to satisfaction. When 
using the IS, their continued usage of the IS can be interpreted as reusing behavior.

\section{Confirmation}

Confirmation is referred to as the realization of the expected benefits of IS use (Oghuma et al., 2016). According to the cognitive dissonance theory (Bhattacherjee, 2001; Festinger, 1957), users may experience cognitive dissonance if usefulness is disconfirmed during actual use. Confirmation will increase perceptions of usefulness while disconfirmation will reduce such perceptions. To reduce dissonance, students using mobile technology for learning health information may try to adjust their perceptions of usefulness. Hence, the following hypothesis is stated:

$\mathrm{H}_{1}$ : Confirmation has a positive effect on perceived usefulness of mobile learning.

Confirmation is based on a rational process of comparing initial expectations with actual experience. Based on the ECM, if users perceive a higher level of concurrence with their post-adoption expectations, they will tend to have a higher level of satisfaction and continuance intention (Bhattacherjee, 2001). Research in social media has suggested that users who are satisfied with their blog experiences are more likely to enjoy using blogs (Shiau and Lou, 2013). Since mobile learning is more enjoyable comparing to traditional learning, students may feel playful in mobile learning environments. Therefore, the confirmation of student expectations will have a positive influence on satisfaction and enjoyment of mobile learning. Hence, the following hypotheses are proposed:

$\mathrm{H}_{2}$ : Confirmation has a positive effect on satisfaction with mobile learning.

$\mathrm{H}_{3}$ : Confirmation has a positive effect on perceived enjoyment of mobile learning.

\section{Perceived Usefulness}

Perceived usefulness, relates to the performance aspect of IS use, has been repeatedly proven to affect behavior and to be a direct determinant of continuance intention usage (Wu and Chen, 2017). Several studies have supported a positive association between perceived usefulness and IS continuance intention (Hung, Chang and Hwang, 2011; Bøe, Gulbrandsen and Søebø, 2015). In addition, social behavioral research suggested that perceived usefulness, communication quality, satisfaction, and perceived playfulness are critical determinants of a customer's attitude toward adoption (Hung et al., 2015). If students perceive mobile learning to be useful, an increased level of satisfaction is expected. The more usefulness users expect to gain from mobile learning, the more satisfied they will be, and the higher the likelihood will be that they will continue using this type of 


\section{Shiue et al.}

learning. Hence, the following hypotheses are proposed:

$\mathrm{H}_{4}$ : Perceived usefulness has a positive effect on satisfaction with mobile learning.

$\mathrm{H}_{5}$ : Perceived usefulness has a positive effect on continuance intention toward mobile learning.

\section{Perceived Enjoyment}

Enjoyment is referred to as the reason or belief formed by an individual's personal experience with the environment (Moon and Kim, 2001). Zhou and Lu (2011) explored the factors affecting mobile instant message user loyalty and concluded that enjoyment significantly influences users' satisfaction toward mobile instant messaging. Mäntymäki and Salo (2011) examined the role of enjoyment on continuance usage intention towards online shopping and find that continuance usage intention is strongly determined by perceived enjoyment. Pindeh et al. (2016) proposed users' acceptance of using mobile apps in learning language is influenced by the usefulness and ease of use, and assumed perceived playfulness would have a significant impact on intention to use mobile apps. Therefore, perceived enjoyment is an important determinant of continuance intention to use mobile devices to learn correct medication use. Hence, the following hypotheses are proposed:

$\mathrm{H}_{6}$ : Perceived enjoyment has a positive effect on satisfaction with mobile learning.

$\mathrm{H}_{7}$ : Perceived enjoyment has a positive effect on continuance intention toward mobile learning.

\section{Satisfaction}

Satisfaction is referred to as an affect and captured as a positive, indifferent, or negative feeling (Bhattacherjee, 2001). Satisfaction intention suggests that higher/lower user satisfaction means that it will be more or less likely that users will have intention to use a system. A review of the educational literature suggests that satisfaction occurs when individuals are confident that a clear understanding of learning is achieved, and their learning results meet or exceed their perceptions of expected outcomes (Hui et al., 2008; Johnson, Aragon and Shaik, 2000). Therefore, if students feel satisfied when they use mobile devices, they will be more likely to continue engaging in mobile learning in the future. Hence, the following hypothesis is proposed:

$\mathrm{H}_{8}$ : Satisfaction has a positive effect on continuance intention toward mobile learning.

According to the above reasoning, the proposed conceptual framework is illustrated in Figure 2.

\section{METHODOLOGY}




\section{-Sample}

The study group of this research consisted of 118 undergraduate students who took an Introduction to Health and Food course in Tainan City, Taiwan. All the students taking the course were informed about this research and were also informed that participation in the research is voluntary. All the data were collected anonymously. A total of 118 students voluntarily participated in the study, 52 of which were males $(44 \%)$ and 66 of which were females $(56 \%)$. All of the students had already used mobile devices either for communication, information, or for self-study.

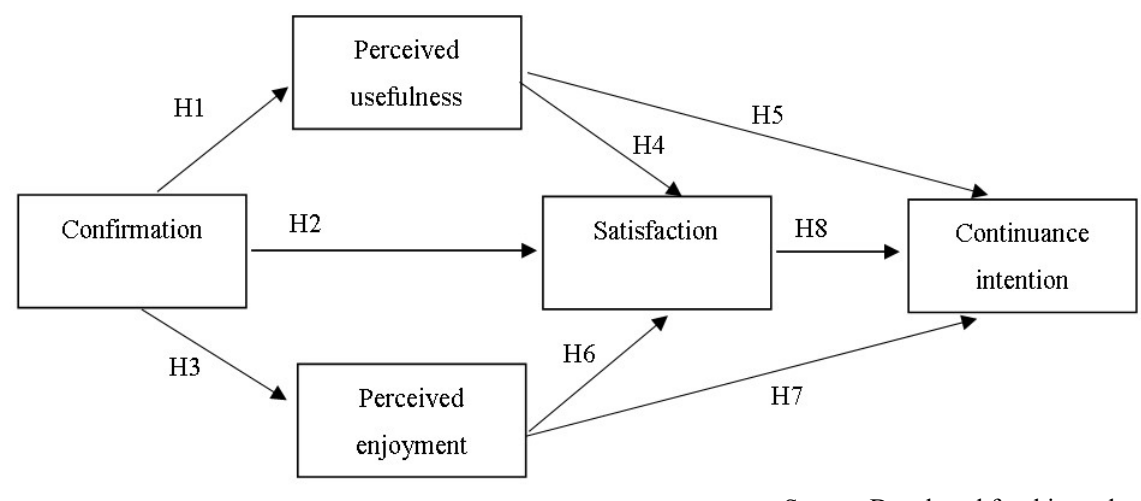

Source: Developed for this study

Figure 2. Research Model

\section{-Instruments}

The instruments were divided into two parts. The first part contained five questions related to the demographic information. The second part consisted of 18 items intended to measure the constructs of expectation (3 items), perceived usefulness (4 items), perceived enjoyment (4 items), satisfaction (4 items), and continuance intention ( 3 items). The participants rated each construct item in part two on a 5-point Likert scale, ranging from 1 (strongly disagree) to 5 (strongly agree). the instrument was revised and adapted, as shown in Table 2, where items from previous studies were modified to fit the mobile learning environment to measure expectation (Bhattacherjee, 2001), perceived usefulness (Davis, 1989), perceived enjoyment (Kim, 2010), satisfaction (Bhattacherjee, 2001), and continuance intention (Bhattacherjee, 2001).

\section{ANALYSIS AND RESULTS}

Partial least squares (PLS) technique was used to analyze the items, variables, the overall research model, and the hypothesized relationships. A factor analysis was used to ensure sufficient reliability 


\section{Shiue et al.}

and validity for the measurements, followed by the structural model analysis. PLS was employed since it seems to be appropriate for exploratory work and for prediction, as well as for analyzing complicated relations and models (Ringle, Sarstedt and Straub, 2012). Also, PLS has a minimal quest on measurement scale, and it does not require a specific distribution of the measured variables. The statistical software SmartPLS was used to analyze the data.

\section{-Measurement Model}

Factor loading and average variance extracted were used to test the convergent validity and reliability of each variable in this study. Table 1 shows that all the constructs exhibited internal consistency, exceeding the threshold value of 0.70 . To satisfy the discriminant validity, the square root of the AVE should be greater than the inter-scale correction. Table 2 shows that the elements along the diagonal were much greater than the off-diagonal elements. In addition, all composite reliabilities (CRs) were > 0.80 , which was greater than the critical value of 0.70 . The analyses confirmed the convergence validity and reliability of the measurement model. Discriminant validity was also confirmed.

\begin{tabular}{cccc}
\hline Variables & Source & Items & Reliability \\
\hline Expectation & Bhattacherjee (2001) & 3 & 0.89 \\
Perceived usefulness & Davis (1989) & 4 & 0.93 \\
Perceived enjoyment & Moon and Kim (2001) & 4 & 0.92 \\
Satisfaction & Bhattacherjee (2001) & 4 & 0.91 \\
Continuance intention & Bhattacherjee (2001) & 3 & 0.94 \\
\hline Source: Calculated for this study & &
\end{tabular}

Table 1. Instruments and Reliability

\begin{tabular}{lccccccc}
\hline \multicolumn{1}{c}{ Constructs } & AVE & CR & $\mathbf{1}$ & $\mathbf{2}$ & $\mathbf{3}$ & $\mathbf{4}$ & $\mathbf{5}$ \\
\hline 1.Confirmation & 0.72 & 0.91 & $\mathbf{0 . 8 4}$ & & & & \\
2.Perceived usefulness & 0.81 & 0.88 & 0.53 & $\mathbf{0 . 7 8}$ & & & \\
3.Perceived enjoyment & 0.84 & 0.92 & 0.43 & 0.67 & $\mathbf{0 . 8 9}$ & & $\mathbf{0 . 9 1}$ \\
4.Satisfaction & 0.81 & 0.94 & 0.48 & 0.52 & 0.37 & 0.32 & $\mathbf{0 . 8 3}$ \\
5.Continuance intention & 0.75 & 0.86 & 0.32 & 0.46 & 0.45 & &
\end{tabular}

Table 2. Correlations Matrix with AVE and CR

\section{-Structural Model}

Figure 3 shows the results of the structural model. We analyzed the $R^{2}$ values to access the explanatory power of the structural model. In this study, we proposed an extended ECM model of students' continuance intention to use mobile learning within correct medication use contexts. The 
model found confirmation to account for 33 percent of the variance in perceived usefulness and 41 percent of the variance in perceived enjoyment. Confirmation, perceived usefulness, and perceived enjoyment together explained 68 percent of the variance in satisfaction. Finally, perceived usefulness together with satisfaction accounted for 52 percent of the variance in continuance intention.

Table 3 shows that seven out of the eight hypotheses were supported according to the PLS analysis. Confirmation had a significant impact on perceived usefulness, satisfaction, and perceived enjoyment, supporting $\mathrm{H} 1, \mathrm{H} 2$, and $\mathrm{H} 3$. Perceived usefulness affected satisfaction and continuance intention, supporting $\mathrm{H} 4$ and H5. Perceived enjoyment affected satisfaction, thus supporting H6. However, perceived enjoyment was not found to have an influence on continuance continuance intent-

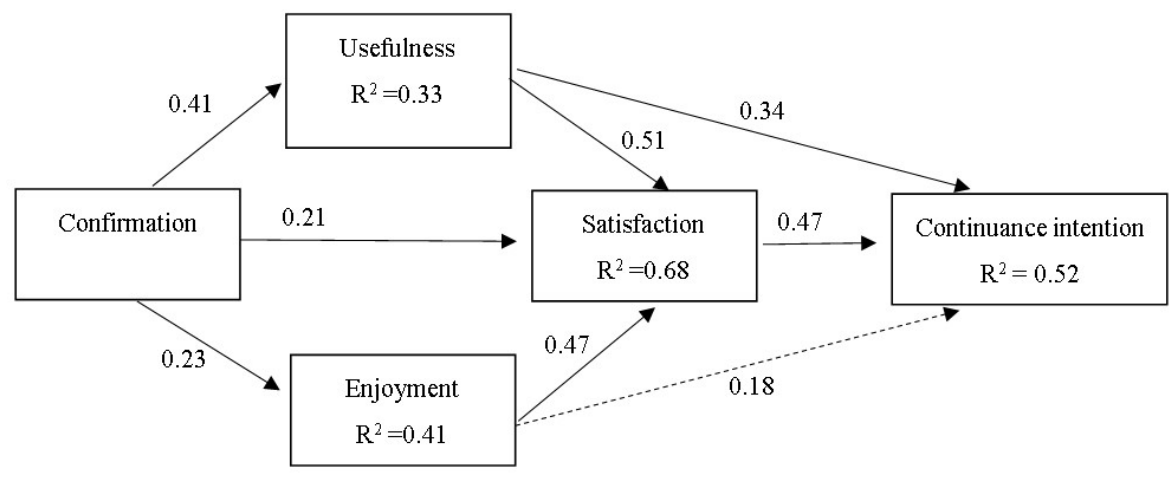

Source: Developed for this study

Figure 3. Path Analysis

ion, so $\mathrm{H} 7$ was not supported. Satisfaction had a higher influence on continuance than perceived usefulness, thus supporting $\mathrm{H} 8$.

\begin{tabular}{lccc}
\hline \multicolumn{1}{c}{ Hypotheses } & $\begin{array}{c}\text { Path } \\
\text { Coefficient }\end{array}$ & $\boldsymbol{p}$-value & Support \\
\hline $\mathrm{H}_{1}:$ Confirmation $\rightarrow$ Perceived usefulness & 0.41 & $p<.001^{* * *}$ & Yes \\
$\mathrm{H}_{2}:$ Confirmation $\rightarrow$ Satisfaction & 0.21 & $p<.01^{* *}$ & Yes \\
$\mathrm{H}_{3}:$ Confirmation $\rightarrow$ Perceived enjoyment & 0.23 & $p<.01^{* *}$ & Yes \\
$\mathrm{H}_{4}:$ Perceived usefulness $\rightarrow$ Satisfaction & 0.51 & $p<.001^{* * *}$ & Yes \\
$\mathrm{H}_{5}:$ Perceived usefulness $\rightarrow$ Continuance intention & 0.34 & $p<.001^{* * *}$ & Yes \\
$\mathrm{H}_{6}:$ Perceived enjoyment $\rightarrow$ Satisfaction & 0.47 & $p<.01^{* *}$ & Yes \\
$\mathrm{H}_{7}:$ Perceived enjoyment $\rightarrow$ Continuance intention & 0.18 & $p>.05$ & No \\
$\mathrm{H}_{8}:$ Satisfaction $\rightarrow$ Continuance intention & 0.47 & $p<.001^{* * *}$ & Yes \\
\hline
\end{tabular}

Source: Calculated for this study

Table 3. Results of Hypotheses Testing

CONCLUSION AND IMPLICATIONS 


\section{Shiue et al.}

Although ECM has been widely useful in studying IS usage, only little research examined its impact on the mobile learning environments. In our study, perceived usefulness and satisfaction could be influential factors for continuance intention to use mobile learning technology. The PLS analysis showed that seven out of eight hypotheses were supported with the significant variances explained, thus providing evidence that the model is effective for analyzing student decisions to continue using mobile learning technology. Our findings suggested that perceived usefulness and satisfaction are salient predictors of continued IS usage are similar to the results of other IS research studies (Bøe et al., 2015; Shiue and Hsu, 2017; Yeh and Teng, 2012).

As shown in the ECM model, satisfaction with mobile learning was the major factor predicting continuance intention, followed by perceived usefulness. The only non-significant relationship found was between perceived enjoyment and continuance. A plausible explanation for this result is the degree to which students are satisfied with mobile learning in regard to their understanding of correct medication usage will affect the degree to which they are more likely to continue using mobile learning to promote their health literacy. These students didn't enjoy learning correct medication usage on their mobile devices. Therefore, the learning content must be improved to make it more enjoyable and motivating.

Mobile devices provide various beneficial features for learning, such as real-time access to information, context sensitivity, instant communication, and feedback. These features may enhance the effects of certain pedagogies, such as self-directed learning, collaborative learning, or formative assessment. This study revealed the continuance intention to use mobile devices for learning correct medication usage. Further efforts are needed to continuously promote living a healthy life in this population. To the best of our knowledge, little research has been conducted to investigate health promotion effectiveness and continuance intention usage from a broad perspective to construct a theoretical framework for such a study.

\section{LIMITATIONS AND FUTURE DIRECTIONS}

This study showed that students were well informed about the correct use of medicines, but their use of medicines still needs improvements. It is suggested that in the future, teachers should strengthen their knowledge of the content and importance of proper medication usage when teaching in schools. Teachers might incorporate new technologies, such as mobile devices and tablets to increase students' learning motivation and enhance students' understanding to proper medication usage through meaningful activities to guide them in the proper use of medicines.

Finally, the population of this study comprised students' who were utilizing mobile learning, for 
which the sample was a total of 118 students in one university. The sample was not drawn randomly from the population, and the sample size was above the required minimal size. Investigating a larger population, however, would provide more reliable results. Thus, the findings of this study should be interpreted cautiously because they may only be applicable to samples with similar characteristics and thus should not be generalized or applied in other contexts.

\section{REFERENCES}

Alrasheedi, M., Capretz, L. F. \& Raza, A. (2015). A systematic review of the critical factors for success of mobile learning in higher education. Journal of Educational Computing Research, 52(2): 257-276.

Bhattacherjee, A. (2001). Understanding information systems continuance: An expectation-confirmation model. MIS Quarterly, 25(3): 351-370.

Bøe, T., Gulbrandsen, B. \& Søebø, $\varnothing$. (2015). How to stimulate the continued use of ICT in higher education: Integrating information systems continuance theory and agency theory. Computers in Human Behavior, 50, 375-384.

Chi, H. Y., Chang, J. C., Yeh, M. K., Chen, C. F., Kang, J. J. \& Ting, H. W. (2012). Enhancing health literacy through developing core abilities of correct medication usage in Taiwan. Journal of Food and Drug Analysis, 20(3): 561-569.

Chi, H. Y., Chang, F. C., Lin, H. J., Huang, L. J., Chang, J. C., Yeh, M. K. \& Kang, J. J. (2014). Evaluation of a healthpromoting school program to enhance correct medication use in Taiwan. Journal of Food and Drug Analysis, 22(1): $271-278$.

Davis, F.D., (1989). Perceived usefulness, perceived ease of use, and user acceptance of information technology. MIS Quarterly, 13, 319-340.

Festinger, L. (1957). A theory of Cognitive Dissonance. Evanston, IL: Row \& Peterson.

Hui, W., Hu, P., Clark, T. H. K., Tam, K. Y. \& Milton, J. (2008). Technology assisted learning: A longitudinal field study of knowledge category, learning effectiveness and satisfaction in language learning. Journal of Computer Assisted Learning, 24(3): 245-259.

Hung, M. C., Chang, I. C. \& Hwang, H. G. (2011). Exploring academic teachers' continuance toward the web-based learning system: The role of causal attributions. Computers and Education, 57(2): 1530-1543.

Hung, S. Y., Hung, H. M., Chang, C. M. \& Tsai, J. C. A. (2015). Cognitive and affective factors influencing customer adoption of social commerce: An empirical study. International Journal of Business and Systems Research, 9(2): 154-178.

Hyman, J. A., Moser, M. T. \& Segala. L. N. (2014). Electronic reading and digital library technologies: understanding learner expectation and usage intent for mobile learning. Education Technology Research Development, 62, 35-52.

Johnson, S.D., Aragon, S.R. \& Shaik, N. (2000). Comparative analysis of learner satisfaction and learning outcomes in online and face-to-face learning environments. Journal of Interactive Learning Research, 11(1): 29-49.

Kim, B. (2010). An empirical investigation of mobile data service continuance: Incorporating the theory of planned behavior into the expectation-confirmation model. Expert Systems with Applications, 37(10): 7033-7039.

King, L., Gardner-McCune, C., Vargas, P. \& Jimenez, Y. (2014). Re-discovering and re-creating African American historical accounts through mobile apps: The role of mobile technology in history education. Journal of Social Studies Research, 38(3): 173-188.

Liu, T. Y., Tan, T. H. \& Chu, Y. L. (2009). Outdoor natural science learning with ab RFID-supported immersive ubiquitous learning environment. Educational Technology and Society, 12(4): 161-175.

Lee, M. C. (2010). Explaining and predicting users' continuance intention toward e-learning: An extension of the expectationconfirmation model. Computers and Education, 54(2): 506-516.

Mäntymäki, M. \& Salo, J. (2011). Teenagers in social virtual worlds: Continuous use and purchasing behavior in Habbo Hotel. Computers in Human Behavior, 27(6): 2088-2097.

Moon, J.W. \& Kim, Y.G. (2001). Extending the TAM for a World-Wide-Web context. Information and Management, 38(4): 217230.

Oghuma, A. P., Libaque-Saenz, C. F., Wong, S. F. \& Chang, Y. (2016). An expectation-confirmation model of continuance intention to use mobile instant messaging. Telematics and Informatics, 33, 34-47.

Oliver, R. L. (1980). A cognitive model of the antecedents and consequences of satisfaction decision. Journal of Marketing Research, 17, 460-469.

Pindeh, N., Suki, N. M. \& Suki, N. M. (2016). User acceptance on mobile apps as an effective medium to learn Kadazandusun language. Procedia Economics and Finance, 37, 372-378.

Ringle, C. M., Sarstedt, M. \& Straub, D. W. (2012). Editor's comments: A critical look at the use of PLS-SEM. MIS Quarterly, 36(1): iii-xiv.

Sharples, M. (2000). The design of personal mobile technologies for lifelong learning. Computers and Education, 34(3): 177193.

Shiue, Y. M. \& Hsu, Y. C. (2017). Digital game's impacts on students' learning effectiveness of correct medication. International Journal of Management, Economics and Social Sciences, 6(S1): 157-165.

Shiau, W. L. \& Lou, M. M. (2013). Continuance intention of blog users: the impact of perceived enjoyment, habit, user involve- 


\section{Shiue et al.}

ment and blogging time. Behavior and Information Technology, 32(6): 570-583.

Song, D. \& Kim, P. (2015). Inquiry-based mobilized math classroom with Stanford mobile inquiry-based learning environment (SMILE). In H. Crompton, \& J. Traxler (Eds.), Mobile learning and STEM: Case studies in practice (pp. 150-161). New York: Routledge.

Sung, Y. T., Chang, K. E. \& Liu, T, C. (2016). The effects of integrating mobile devices with teaching and learning on students' learning performance: A meta-analysis and research synthesis. Computers and Education, 94, 252-275.

Wu, B. \& Chen, X. H. (2017). Continuance intention to use MOOCs: Integrating the technology acceptance model (TAM) and task technology fit (TTF) model. Computers in Human Behavior, 67, 221-232.

Yeh, K. J. \& Teng, T. C. (2012). Extended conceptualization of perceived usefulness: empirical test in the context of information system use continuance. Behavior and Information Technology, 31(5): 525-540.

Zhou, T. \& Lu, Y. (2011). Examining mobile instant message user loyalty from the perspective of network externalities and flow experience. Computers in Human Behavior, 27(2): 883-889. 